\title{
Robotic Lymphadenectomy During Pancreatoduodenectomy with First Superior Mesenteric Artery Dissection
}

\author{
R. Memeo, MD, PhD ${ }^{1,2,3,4}$, V. De Blasi, $\mathrm{MD}^{1,2,3}$, O. Perotto, $\mathrm{MD}^{1,2}$, D. Mutter, MD, $\mathrm{PhD}^{1,2,3}$, J. Marescaux, MD, \\ FACS, (Hon) FRCS, (Hon) FJSES ${ }^{1,2,3}$, and P. Pessaux, MD, PhD ${ }^{1,2,3,4}$ \\ ${ }^{1}$ Unité de chirurgie Hépato-biliaire et pancréatique, service de chirurgie digestive et endocrinienne, Nouvel Hôpital Civil, \\ Strasbourg, France; ${ }^{2}$ IRCAD, Institut de recherche contre les cancers de l'appareil digestif, Strasbourg, France; ${ }^{3} \mathrm{IHU}$ \\ (Institut Hospitalo-Universitaire) de Strasbourg de chirurgie mini-invasive guidée par l'image, Strasbourg, France; \\ ${ }^{4}$ INSERM U1110, Strasbourg, France
}

\begin{abstract}
Background. An expert consensus meeting had defined the standard lymphadenectomy during pancreatoduodenectomy for an adenocarcinoma of the head of the pancreas. There is a controversy regarding the possibility to perform this optimal lymphadenectomy by minimally invasive approach.

Patients. The patient was a 68-year-old man with the diagnosis of an adenocarcinoma of the head of the pancreas. The 3D reconstructions evidenced the existence of a right hepatic artery.

Technique. The patient was positioned in the French position with the assistant between the legs and the robot at the head. Five trocars were used; the camera was introduced through the umbilicus trocar. The operation began with a peritoneal and liver exploration, and with an interaortico-caval picking. Because lymph nodes were noninvaded, pancreatoduodenectomy was decided with the first dissection of the superior mesenteric artery helped with a hanging maneuver. The right hepatic artery was dissected.
\end{abstract}

Each structure of the hepatic pedicle was skeletonized. The camera was switched to the right side. The first jejunal loop was divided with a stapler. The specimen was totally mobilized en bloc, freed from the portal vascular axis with a dissection of the right border of the coeliac trunk. The pancreas was divided. At the end of the dissection, the different arterial and venous structures were skeletonized with a resection of the lymph node group $5-6-8_{\mathrm{a}^{-}}-12_{\mathrm{a}, \mathrm{b}, \mathrm{c}^{-}}$ $13_{\mathrm{a}, \mathrm{b}}-14_{\mathrm{a}, \mathrm{b}}-17_{\mathrm{a}, \mathrm{b}}$. Pathology confirmed R0 resection for a well-differentiated pancreatic adenocarcinoma graded pT3N1 (5/20).

Conclusions. Robotic pancreatoduodenectomy could be performed with an optimal standard lymphadenectomy as recommended by the expert consensus.

DISCLOSURE The authors have no conflicts of interest or financial ties to disclose.
Electronic supplementary material The online version of this article (doi:10.1245/s10434-016-5421-y) contains supplementary material, which is available to authorized users.

(C) Society of Surgical Oncology 2016

First Received: 29 March 2016;

Published Online: 26 July 2016

P. Pessaux, MD, PhD

e-mail: patrick.pessaux@chru-strasbourg.fr 